\title{
Additive Manufacturing and Hot-fire Testing of Bimetallic GRCop-84 and C-18150 Channel-Cooled Combustion Chambers using Powder Bed Fusion and Inconel 625 Hybrid Directed Energy Deposition
}

\author{
Paul R. Gradl ${ }^{1}$, Chris Protz ${ }^{2}$ \\ NASA Marshall Space Flight Center, Huntsville, AL 35812 \\ Kevin Zagorski ${ }^{3}$, Vishal Doshi ${ }^{4}$,Hannah McCallum ${ }^{5}$ \\ Virgin Orbit, Long Beach, CA 90808
}

Additive manufacturing (AM) is an advanced fabrication technique that is demonstrating tremendous potential to reduce fabrication lead times and costs for liquid rocket engine components. The additive manufacturing technology lends itself to fabricate components with complex features such as internal coolant channels in combustion chambers that would otherwise require complex manufacturing operations. A requirement for high performance engines is to use high conductivity, high strength materials such as copperalloys for combustion chamber liners to provide adequate wall temperatures and meet subsequent structural margins. A further requirement of this configuration is to minimize weight by defining and fabricating material in discrete locations as required. NASA and Industry partner, Virgin Orbit, have been working to advance these technologies through development of bimetallic additive manufacturing techniques under a publicprivate partnership through NASA's Announcement of Collaborative Opportunity (ACO). This partnership is advancing a bimetallic hybrid additively manufactured combustion chamber that integrates Powder Bed Fusion (PBF), specifically Selective Laser Melting (SLM), and Directed Energy Deposition (DED) blown powder techniques to optimize the chamber materials and subsequent assembly. The SLM process is being developed for the combustion chamber liner to use copper-alloys GRCop-84 (Copper-Chrome-Niobium) or C18150 (Copper-Chrome-Zirconium). The hybrid DED blown powder technology is used to apply an integrated structural jacket and manifolds using an Inconel 625 superalloy on the outer surface of the SLM copper liner. The hybrid DED technology being used on this program is a DMG Mori Seiki AM machining center which integrates the DED blown powder with an integral subtractive (traditional) machining to minimize overall setups. A series of chambers were fabricated using these techniques with GRCop-84/Inconel 625 and C18150/Inconel and hot-fire tested at NASA Marshall Space Flight Center (MSFC) in LOX/Kerosene (RP-1). This paper describes the process development to integrate these AM technologies into an integrated bimetallic assembly, the design of the chamber, results from hot-fire testing, and further development.

\section{Nomenclature}

$\begin{array}{ll}\mathrm{AM} & =\text { Additive Manufacturing or Additively Manufactured } \\ \mathrm{C}-18150 & =\text { Copper-Chrome-Zirconium Alloy }(\mathrm{Cu}-\mathrm{Cr}-\mathrm{Zr}) \\ \mathrm{DED} & =\text { Directed Energy Deposition } \\ \text { EBF }^{3} & =\text { Electron Beam Freeform Fabrication } \\ \text { GRC } & =\text { Glenn Research Center }\end{array}$

\footnotetext{
${ }^{1}$ Senior Combustion Devices Engineer, Component Technology Branch, Senior Member, AIAA

${ }^{2}$ Team Lead, Propulsion Detailed Design

${ }^{3}$ Advanced Propulsion Manufacturing Manager

${ }^{4}$ Combustion Devices Development Engineer

${ }^{5}$ Combustion Devices Development Engineer
} 


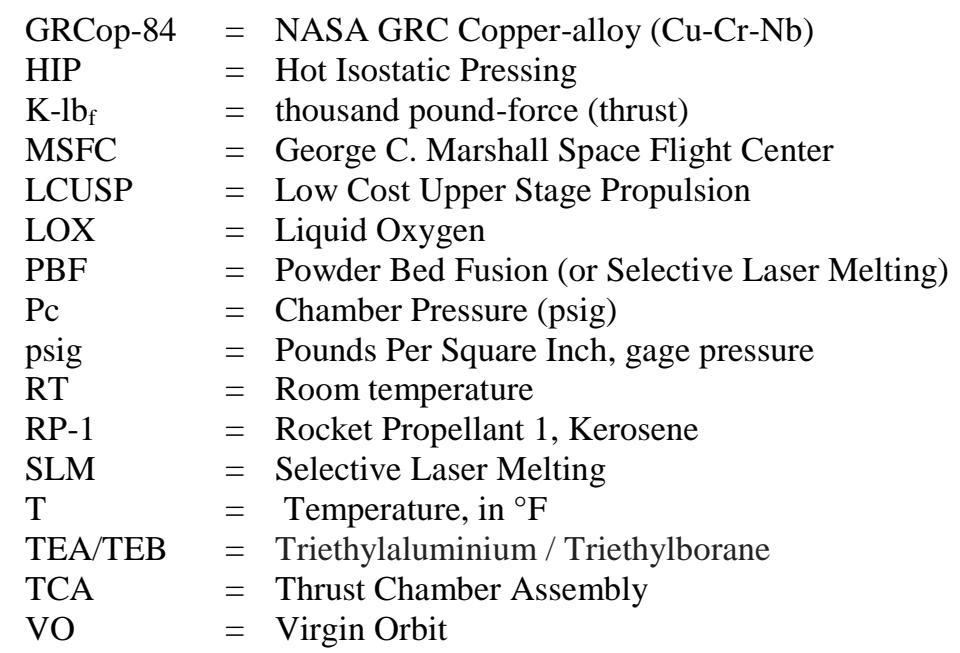

\section{Introduction}

Combustion chambers are the core component of liquid rocket engines to provide thrust and operate in extreme temperature, pressure, and oxidation environments. This environment presents significant challenges for the chamber design and requires unique manufacturing processes and materials. Combustion chambers are regeneratively-cooled with the propellant utilized within the engine cycle to integrally cool the chamber walls maintaining adequate wall temperatures and provide a temperature increase to the propellant to promote injector performance. The various thermal and structural loads within the chamber require discrete materials to be used in the design and fabrication for the liner, structural jacket, and fluid distribution manifolds. The liner of the chamber is fabricated using copper-alloy materials for high performance engines due to the need for high conductivity to dissipate heat providing adequate wall temperatures with combined high strength to meet subsequent structural margins. High strength superalloys or stainless-based compatible materials are used for the structural jacket and distribution manifolds. The design must integrate the fabrication using these materials to meet required performance in the environment and minimize overall weight.

Traditional manufacturing methods for combustion chambers have focused on an integrally machined and slotted copper-liner where the coolant channels are closed out using a brazing or electroplating process. There are several challenges using each of these processes including lead time for wrought materials and processing, tight tolerances for component assembly, specialized fabrication equipment, tooling, and obsolescence. Modern fabrication techniques such as additive manufacturing (AM) are providing new opportunities to fabricate components and assemblies that were not previously possible. AM provides a method for rapid fabrication of the chamber liner and closeout of the coolant channels that would otherwise require several processing steps and bonding methods for a complete chamber assembly, while providing minimum thermophysical and structural material properties. While AM provides significant advantages, it is still a newer technology and requires development and process maturity before full implementation into flight applications such as Virgin Orbit's LauncherOne vehicle.

Virgin Orbit's current Newton 3 and Newton 4 engines for the LauncherOne vehicle use a traditional combustion chamber manufacturing approach for the purpose of leveraging the significant flight heritage and reliability of these methods. While development using the traditional technology evolved, Virgin Orbit sought opportunities to significantly reduce cost and fabrication lead time, as well as to improve performance via material optimization of chambers using additive manufacturing techniques and installed a dedicated hybrid directed energy deposition (DED) DMG Mori machining center. Development using this technology for chamber closeout and jacket application is being matured. Independently, NASA had initiated a program called Low Cost Upper Stage Propulsion (LCUSP) to develop the process for additive manufacturing of GRCop-84 using selective laser melting (SLM) and applying a Inconel 625 structural jacket using Electron Beam Freeform Fabrication ( $\left.\mathrm{EBF}^{\wedge} 3\right)$. Based on an ideal partnership to integrate all these technologies into a potential flight program, Virgin Orbit and NASA partnered to develop the hybrid additive manufacturing technology for combustion chambers.

In 2018, Virgin Orbit was awarded a partnership agreement under the NASA Space Technology Mission Directorate (STMD) Announcement for Collaborate Opportunity (ACO). The ACO program was established to promote public private partnerships and industry to make use of NASA-developed technology and the use of NASA 
facilities and engineering expertise. Although no funds are exchanged during the ACO contract, each partner puts in an equal contribution to develop the technology. The core of the ACO partnership was to develop and test various copper-alloys and integrate into a bimetallic combustion chamber assembly using selected hybrid additive manufacturing technologies. The outcome of the program was to complete fabrication of several bimetallic combustion chambers and complete hot-fire testing to determine performance. The NASA contributions were to develop an additive manufacturing process for GRCop84, C-18150, and GRCop-42 copper-alloys, materials testing and characterization, chamber design consultation, and hot-fire testing ${ }^{1}$. Virgin Orbit contribution design and fabrication of the bimetallic structural jacket using their hybrid additive manufacturing technology, integration of the chamber assembly, and hot-fire testing.

In order to evaluate manufacturing techniques prior to committing to full-size engine hardware, Virgin Orbit and NASA MSFC collaborated on the development of a subscale thrust chamber demonstrator based on the $2 \mathrm{k}-\mathrm{lb}_{\mathrm{f}}$ thrust workhorse chamber designed by NASA MSFC. The chamber liners were SLM-printed in GRCop-84 and C18150 copper alloys with an Inconel 625 structural jacket and coolant manifold interface joints additively applied with directed energy deposition (DED) at Virgin Orbit ${ }^{2}$. The jacket and manifold interfaces were also machined in-situ by use of the subtractive manufacturing functions of Virgin Orbit's DMG-Mori LT4300 hybrid machine tool. Fabrication was completed of these chambers and hot-fire testing was completed in December 2018. This paper will present an overview of the development, chamber hardware and hot-fire testing results.

\section{SLM and DED Process Development}

\section{A. Overview of SLM GRCop-84 and C-18150}

Combustion chamber liners fabricated using a copper-alloy are necessary for high performance engines due to the need for high conductivity to dissipate heat and provide adequate wall temperatures combined with high strength to meet subsequent structural margins. AM provides a method for rapid fabrication of the chamber liner and closeout of the coolant channels that would otherwise require several processing steps and bonding methods for a complete chamber assembly, while providing minimum thermophysical and structural material properties ${ }^{3}$. A common copperalloy used for combustion chambers is $\mathrm{C}-18150(\mathrm{Cu}-\mathrm{Cr}-\mathrm{Zr})$, providing the necessary conductivity and strength for chamber environments. However, C-18150 can be limited in use due to oxidation and reduced strength at elevated temperatures ${ }^{4}$. Alternate copper alloys, GRCop-84 and GRCop-42, were developed at NASA Glenn Research Center (GRC) as an improvement over some of the traditional copper alloys available ${ }^{5,6,7}$. The elemental composition of these copper alloys can be found in Table 1 .

Table 1. Elemental Composition of Copper-alloys (percent weight) ${ }^{8,9}$

\begin{tabular}{c|ccc} 
Element & GRCop-84 & C-18150 & GRCop-42 \\
\hline \hline $\mathrm{Cr}$ & $6.2-6.8$ & $0.5-1.5$ & $3.1-3.4$ \\
$\mathrm{Nb}$ & $5.4-6.0$ & - & $2.7-3.0$ \\
$\mathrm{Cu}$ & Balance & Balance & Balance \\
$\mathrm{Zr}$ & - & $0.05-0.2$ & -
\end{tabular}

The copper-alloys selected for initial development were the C-18150 and GRCop- 84 due to their maturity at time of the partnership. It was determined to further mature the GRCop-42 alloy in parallel providing an option to the GRCop-84 with higher conductivity. SLM is a layer by layer additive manufacturing process. The process starts with a 3D-CAD model that is sliced into thin 2D layers that defines the laser toolpath for sintering the part. A thin layer, typically 30-45 microns, of metal powder is spread across the build area and a fine focus laser rasters and melts (or sinters) the area that defines the part cross section at that particular layer ${ }^{10,11}$. A build plate is required to initiate the process so the material has something to bond to.

After a layer is completed the build plate is lowered slightly and a new layer of powder is spread and the laser sinters the new build layer. Sufficient power is used to penetrate into previous build layers allowing proper bonding between layers. The process is repeated thousands of times until the part is fully fabricated or grown. This allows for the complex internal features to be fabricated, such as the coolant channels. Varying parameters are used for the infill (internal material) and the contouring (surfaces inboard or outboard) for a component. An example of the contouring 
and infill sintering using GRCop-84 can be seen in Figure 1. The entire build is completed in an inert environment that limits oxidation of the melt pool.

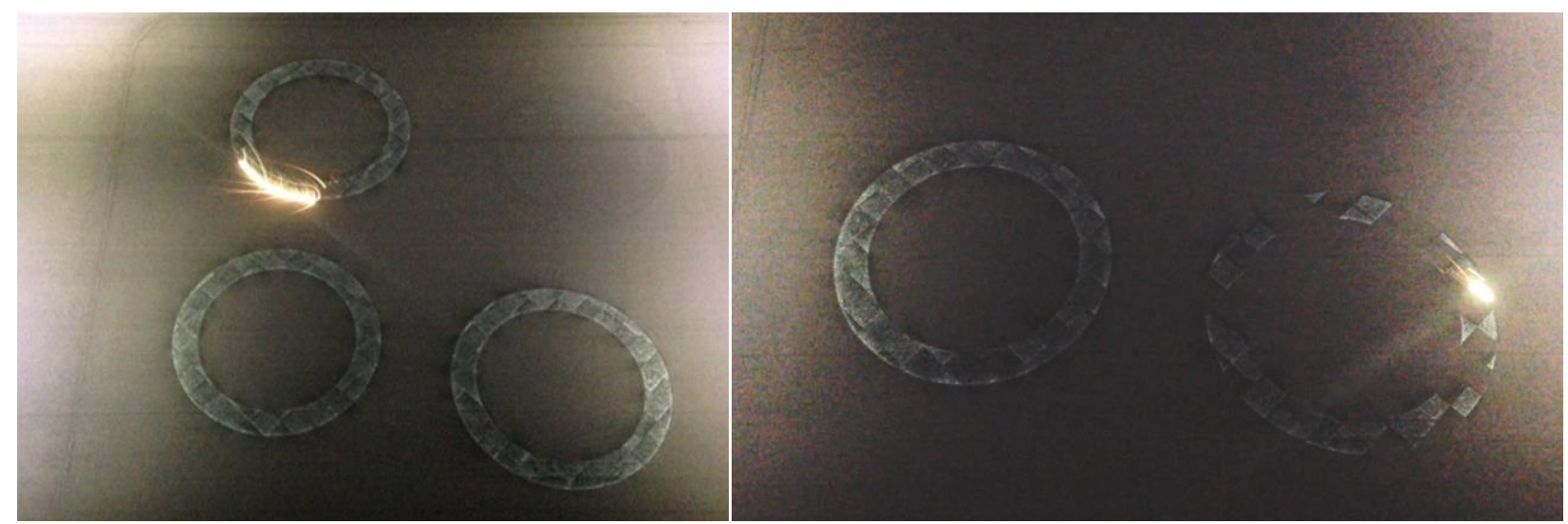

Figure 1. SLM GRCop-84 Chamber Fabrication showing the (Left) Contouring Pass and (Right) In-fill Pass.

Several materials have been matured for flight applications using the SLM process, but copper-alloys are considered a newer development in the last 5 years using this process. NASA MSFC and GRC started development of the GRCop-84 in 2014 under the LCUSP program and demonstrated the ability to successfully print high density material and completed hot-fire testing of 35,000 lb thrust-class bimetallic combustion chambers in 2017 and 2018. Following the LCUSP program, the GRCop-84 material has been successfully used for several NASA development programs demonstrating the use of the technology in various propellants and test conditions. The GRCop- 84 has an extensive database of material properties that were able to be used for the design and development. Additionally, the SLM GRCop-84 printing process was picked up by several commercial additive manufacturing service vendors making it further accessible providing new opportunities for commercial space companies.

The C-18150 material started development with commercial printing service vendors a couple years after the development of the GRCop- 84 . The C-18150 used an identical process as the GRCop- 84 and GRCop-42 for SLM fabrication. There were some early challenges observed in the printing process though compared to the GRCop-84. It was observed that the powder seemed to oxidize more readily than the GRCOp-84, so handling in inert environments was much more critical. The $\mathrm{C}-18150$ was required more extensive research into the optimization of heat treatments. Where the GRCop-84 only requires a Hot Isostatic Pressing (HIP) operation after SLM, the C-18150 requires a HIP, Solution, and Aging cycle to achieve the mechanical and thermophysical properties.

Several mechanical test specimens and chambers were fabricated internal at MSFC and also several industry vendors. The GRCop- 84 was tested in the HIP'd condition, while the C-18150 went through a HIP, solution, and aging. There is likely continued development required to optimize the heat treatment, but the C-18150 showed a lot of scatter in the data, particularly elongation. The typical tensile properties at room temperature (RT) are shown in Table 2. While some of the values were lower than expected in the C-18150, it was determined to still move forward with development on these units.

Table 2. Typical properties at RT of SLM GRCop-84, GRCop-42, and C-18150.

\begin{tabular}{lccc}
\multicolumn{1}{c}{ Material } & $\begin{array}{c}\text { Tensile } \\
(\mathbf{k s i})\end{array}$ & $\begin{array}{c}\text { Yield } \\
(\mathbf{k s i})\end{array}$ & $\begin{array}{c}\text { Elongation } \\
(\boldsymbol{\%})\end{array}$ \\
\hline \hline GRCop-84 - SLM, MSFC Concept M2 & 56.6 & 30.2 & 30 \\
GRCop-84 - SLM, vendor & 64.6 & 34.2 & 26 \\
GRCop-42 - SLM, MSFC Concept M2 & 52 & 25.1 & 32.2 \\
C-18150 - SLM, vendor & 40 & 26 & 27
\end{tabular}




\section{B. Overview of Directed Energy Deposition (DED) Jacket}

NASA had previously demonstrated the use of a bimetallic jacket using the Electron Beam Freeform Fabrication $\left(\mathrm{EBF}^{3}\right.$ ) by Langley Research Center (LaRC) under the LCUSP program. Under LCUSP a GRCop-84 SLM liner was fabricated in 2-pieces and an Inconel 625 jacket was applied ${ }^{12}$. The $\mathrm{EBF}^{3}$ uses a wire-fed electron beam energy deposition approach and applied the Inconel 625 structural jacket on the length of the chamber including the manifold preparations. The manifolds were then traditionally welded using Electron Beam (EB) welding. There were several lessons learned about the development including shrinkage of the throat and overall length. An example of the development under the LCUSP program can be seen in . One challenge with the $\mathrm{EBF}^{3}$ was the high heat input required with the electron energy source to achieve good penetration of the Inconel 625 into the copper ${ }^{13}$.
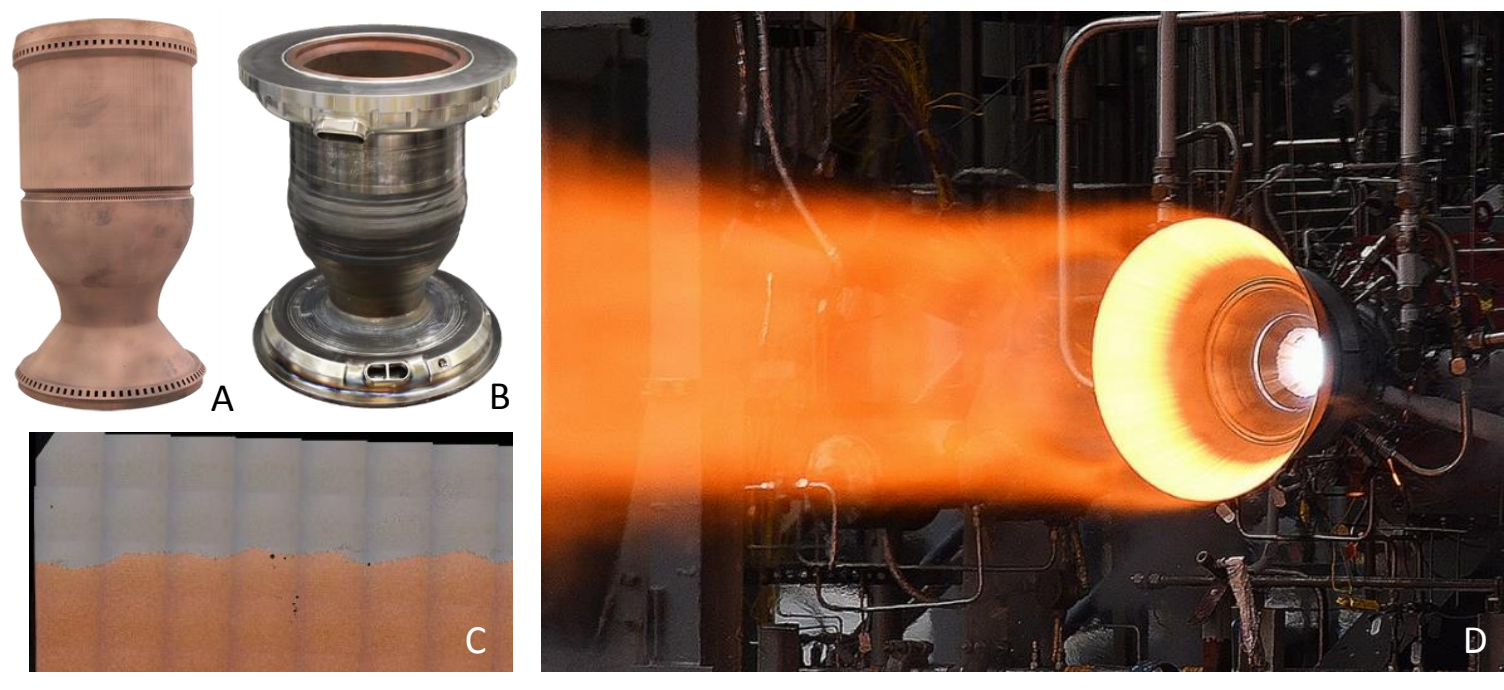

Figure 2. NASA's Bimetallic chamber development under the LCUSP Project: A) 2-piece SLM GRCop-84 Liner, B) $\mathbf{E B F}^{3}$ structural jacket applied, C) Typical bimetallic joint using $\mathbf{E B F}^{3}$, D) Hot-fire testing of 35K-lbf thrust-class Thrust Chamber Assembly (TCA).

There were some opportunities that Virgin Orbit and NASA saw with the bimetallic chamber development and one of the reasons for the partnership ${ }^{14}$. Virgin Orbit invested in a unique hybrid technology using blown powder directed energy deposition (DED) and integral machining. Virgin Orbit's DED process involves the use of a DMGMori LT4300 machine, employing an infrared-wavelength diode laser which acts to create a melt pool in the surface of the substrate materials. This molten area is filled by an adjacently-positioned nozzle that directs a flow of metal powder into the melt pool, diffusing into the substrate and causing a buildup of fully melted powder particles on the surface. The CNC toolpath of the AM deposition head controls the area over which additive material is applied in the same way a milling tool is guided to remove material on a typical multi-axis machine tool. An overview of the blown powder DED process can be seen in Figure 3 and example of the Virgin Orbit DMG LT4300 in Figure 4.

There are a wide variety of DED parameters which are varied to achieve the desired layer thickness and level of adhesion to a substrate. Some of the primary parameter variables include:

- Melt pool temperature (a function of laser power output)

- Mass flow rate of powder exiting the nozzle

- Inert carrier gas flow rate

- Deposition head feed rate along the substrate surface

- Overlap of adjacently deposited layers (known as "stepover")

Powder feed stock for this DED method is substantially larger and acceptable in a wider range of size than what is required for SLM additive manufacturing. While SLM tends to specify feed stock particle size in the range of 20$40 \mu \mathrm{m}$, typical DED stock is in the range of 50-150 $\mu \mathrm{m}$. This is made possible by the higher power energy source used (up to $10 \mathrm{~kW}$ is not unheard of) as compared to SLM (typically $400 \mathrm{~W}-2 \mathrm{~kW}$ ). The larger band of acceptable particle size also results in reduced cost for DED powder an provides practical benefits in the area of machine operator safety since the ability of the heavier material to become an atomized exposure hazard for machine operators is reduced. 


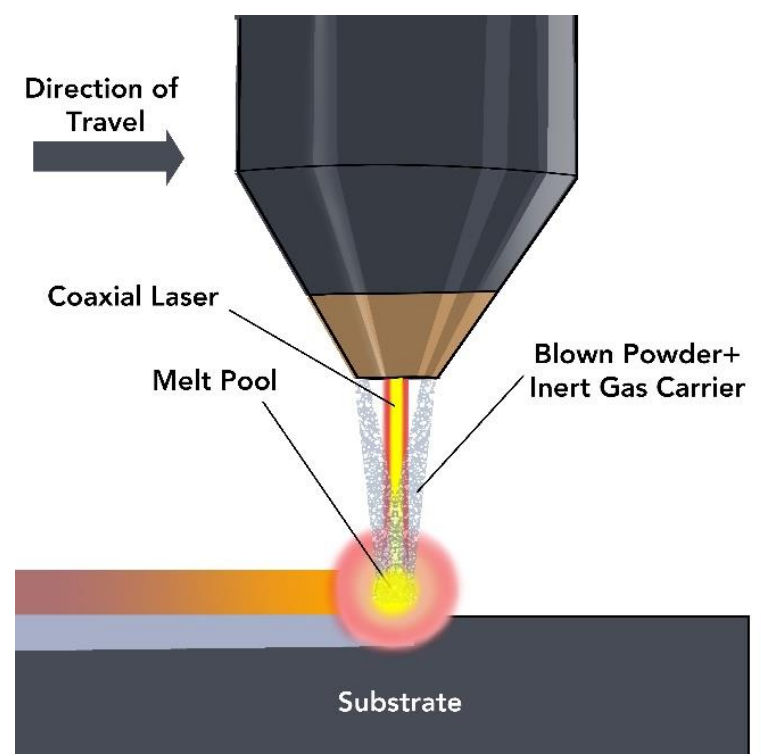

Figure 3. Overview of blown powder DED process.

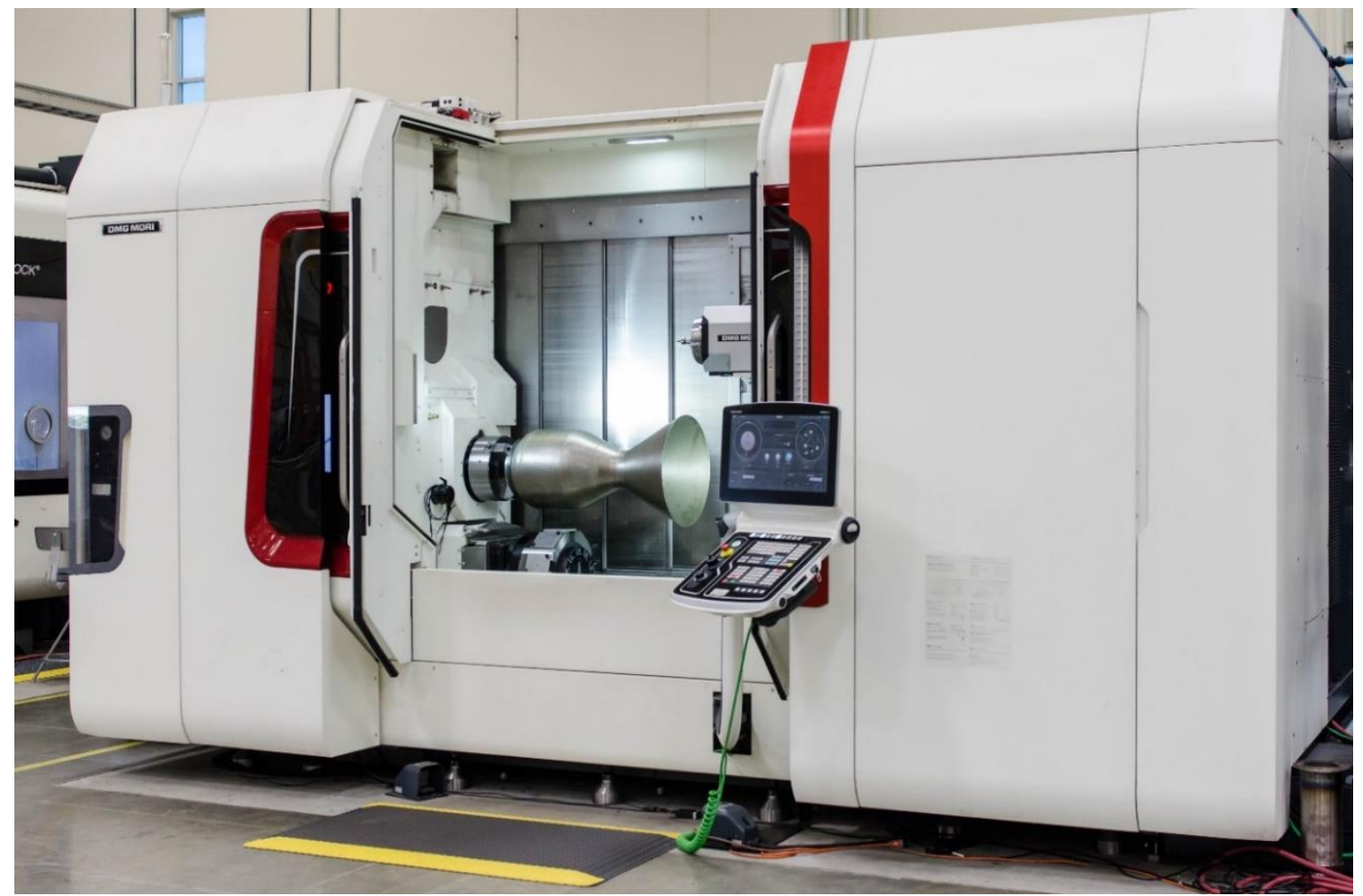

Figure 4. External view of the Virgin Orbit LT4300 Hybrid Manufacturing Machine.

For the purposes of applying the structural jacket, the DED was utilized. The immediate benefit of DED lies in its ability to incorporate multi-material additive into the thrust chamber hardware which is a feature not available within standard SLM processes. The jacket material chosen for this application was the nickel-base superalloy Inconel 625 due to, among other reasons, its strength retention at elevated temperature, lack of complex post-build thermal processing requirements, and ready availability in powder form. Significant development work was completed to characterize the DED Inconel 625 material including mechanical test properties and heat treatments. The integral machining operations were also utilized where necessary in the process during development. 


\section{Hardware Development}

The SLM GRCop-84 and C-18150 liner were designed for water cooling and planned to be tested in Liquid Oxygen/Kerosene (LOX/RP-1). The liner design and manifolds were based on previously tested designs in LOX/Hydrogen and fabricated in three pieces. The channels were designed to meet generally-accepted SLM additive manufacturing rules of thumb. This included checks to ensure that unsupported features were within $45^{\circ}$. The initial design of this SLM liner had additional stock on the outside surface to allow for an appropriate thickness of cladding layer. If the liner closeout is too thin, there is potential for the initial jacket deposition layer to penetrate into the channels. This was one of the lessons learned under the LCUSP chamber fabrication and observed during hot-fire testing ${ }^{15}$. The configuration and part numbers for the liners are shown in Table 3. A total of 3 chambers were fabricated, but only 2 were tested. The second configuration (VO2) was identical to VO1, but was later decided to focus more of the hot-fire testing on VO1 and VO3.

Table 3. Configuration of Chambers for Testing.

\begin{tabular}{lcc} 
& $\begin{array}{c}\text { Virgin Orbit \#1 } \\
\text { (VO1) }\end{array}$ & $\begin{array}{c}\text { Virgin Orbit \#3 } \\
\text { (VO3) }\end{array}$ \\
\hline \hline SLM Liner Material & GRCop-84 & C-18150 \\
Heat Treatment & HIP & HIP, Solution, Age \\
Jacket Material & Inconel 625 & Inconel 625
\end{tabular}

The GRCop-84 and C-18150 liners were fabricated at both MSFC and After printing was complete the powder was removed with shop air blown down each channel and Computer Tomography (CT) scanned. It is generally best practice to use $\mathrm{CT}$ at intermittent sections of the chamber to verify all channels are clear. The liners then went through the appropriate heat treatments including HIP for the GRCop- 84 and HIP, solution and aging for the C-18150. The liners in the as-built conditions can be seen in Figure 5.

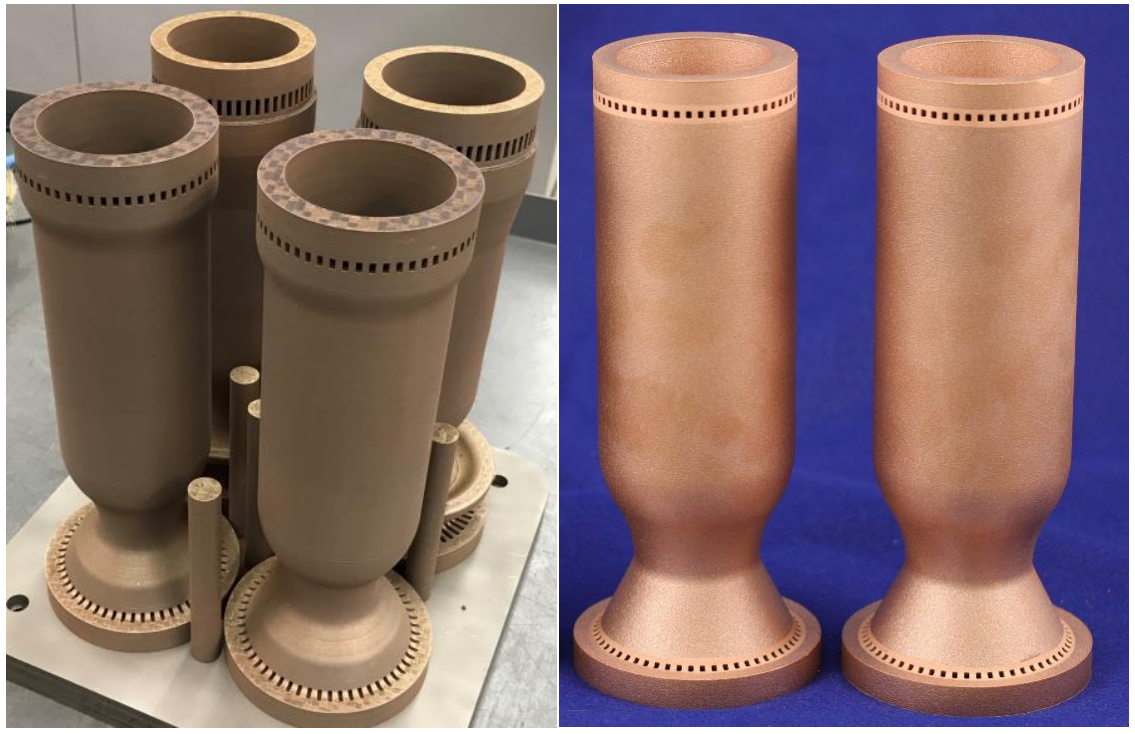

Figure 5. SLM Liners in as-built condition, (Left) GRCop-84 liners after powder was cleared and (Right) $\mathrm{C}-18150$ liners after powder cleared and grit blasting.

Following the SLM process the liners were sent to Virgin Orbit and the DED process was completed to finish the structural jacket. The structural jacket was completed in a single setup operation on the DMG LT4300 with the DED and machining processes completed. The installation of the liner and establishment of datums, cladding operations and final machining operations can be seen in Figure 6. Following machining of the jacket, the manifolds were EB welded and the final configuration also seen in Figure 6. The chambers were left in the as-deposited condition. One observation made during DED additive operations was that as a result of the high heat input required to bond the jacket material to the copper alloy there was some non-trivial geometric deformation of the liner, but provided appropriate dilution of the Inconel 625 into the copper-alloy ${ }^{16}$. 

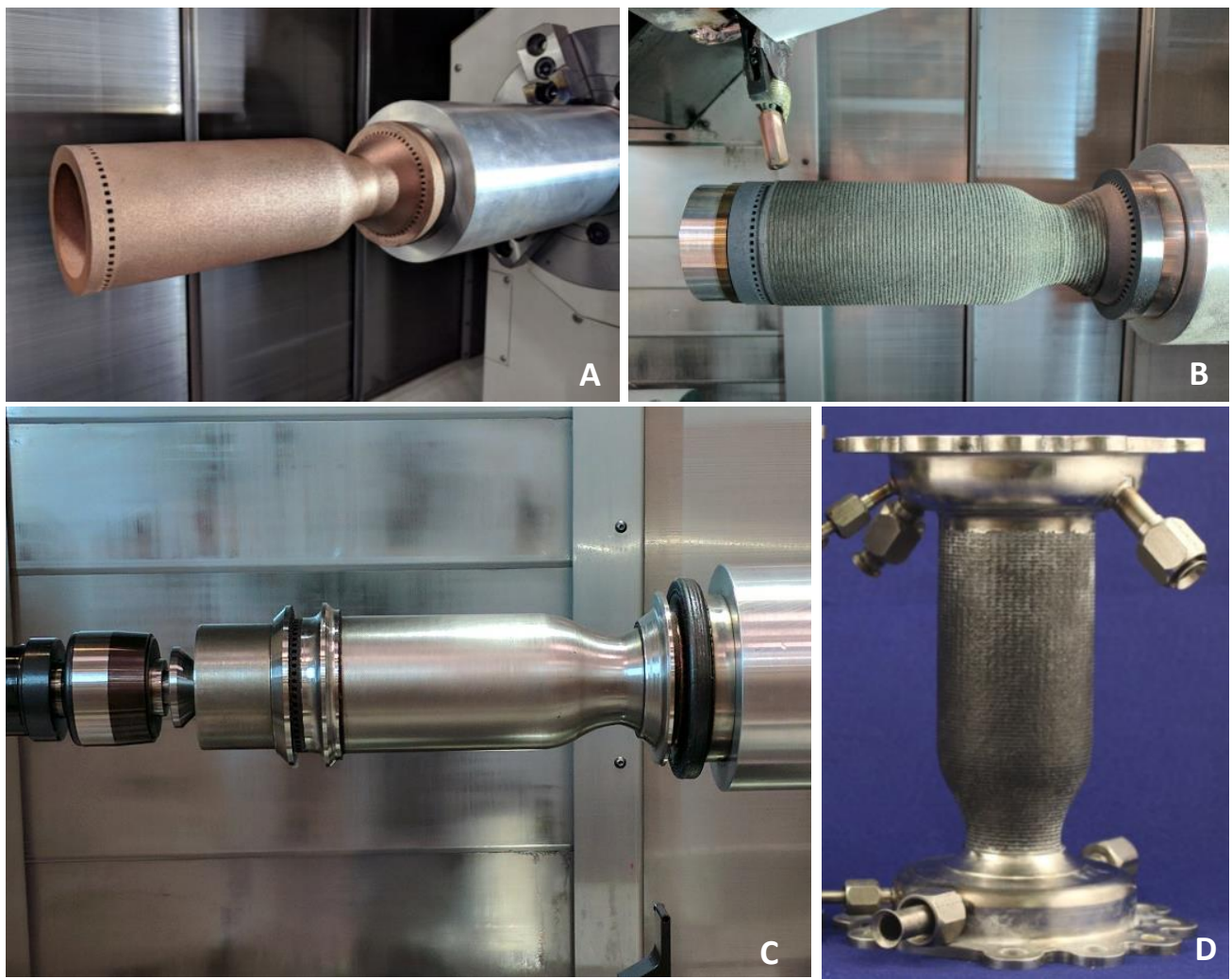

Figure 6. DED cladding operations to apply the Inconel 625 structural jacket: A) Establishing datums in the DMG LT4300, B) Initial DED passes of the liner, C) Final machining of the liner, and D) Final configuration of the chamber.

\section{Hot-fire Testing}

A hot-fire test program was established to complete the testing of the chambers built under the ACO partnership. The testing was planned to be completed at MSFC Test Stand 115 (TS115). The program, PJ024, used LOX/RP-1 and a triplet configuration impinging injector. The impinging injector was additively manufactured and tested under prior programs ${ }^{17}$. The chamber pressures $(\mathrm{Pc})$ varied from $539 \mathrm{psig}$ to $1,080 \mathrm{psig}$. The mixture ratio (MR), LOX/RP-1, was varied from 2.22 to 2.84. TEA/TEB ignition was used for all testing and a total of 20 tests were completed accumulating over 880 seconds. A summary of test data can be seen in Table 4.

Table 4. Summary of test results for bimetallic chambers VO1 and VO3.

\begin{tabular}{lcccc} 
& $\begin{array}{c}\text { Peak Chamber } \\
\text { Pressure (psig) }\end{array}$ & $\begin{array}{c}\text { Peak } \\
\text { MR }\end{array}$ & Starts & $\begin{array}{c}\text { Accumulated } \\
\text { Time (sec) }\end{array}$ \\
\hline \hline VO Chamber 1 (VO1) & 1,048 & 2.84 & 11 & 475 \\
VO Chamber 3 (VO3) & 1,080 & 2.84 & 9 & 405
\end{tabular}

Prior to testing, the chambers passed post-build clearance checks including water flow and pressure proof of the regenerative cooling channel circuit. Channel discharge coefficients were calculated through water flow testing and confirmed to be in-family with analytical and empirical values for the flow passages of this hardware, suggesting that heat input from the jacket cladding did not contribute to any significant deformation of the cooling passages internal to the copper liner. The completed chamber installed in the test stand can be seen in Figure 7. 

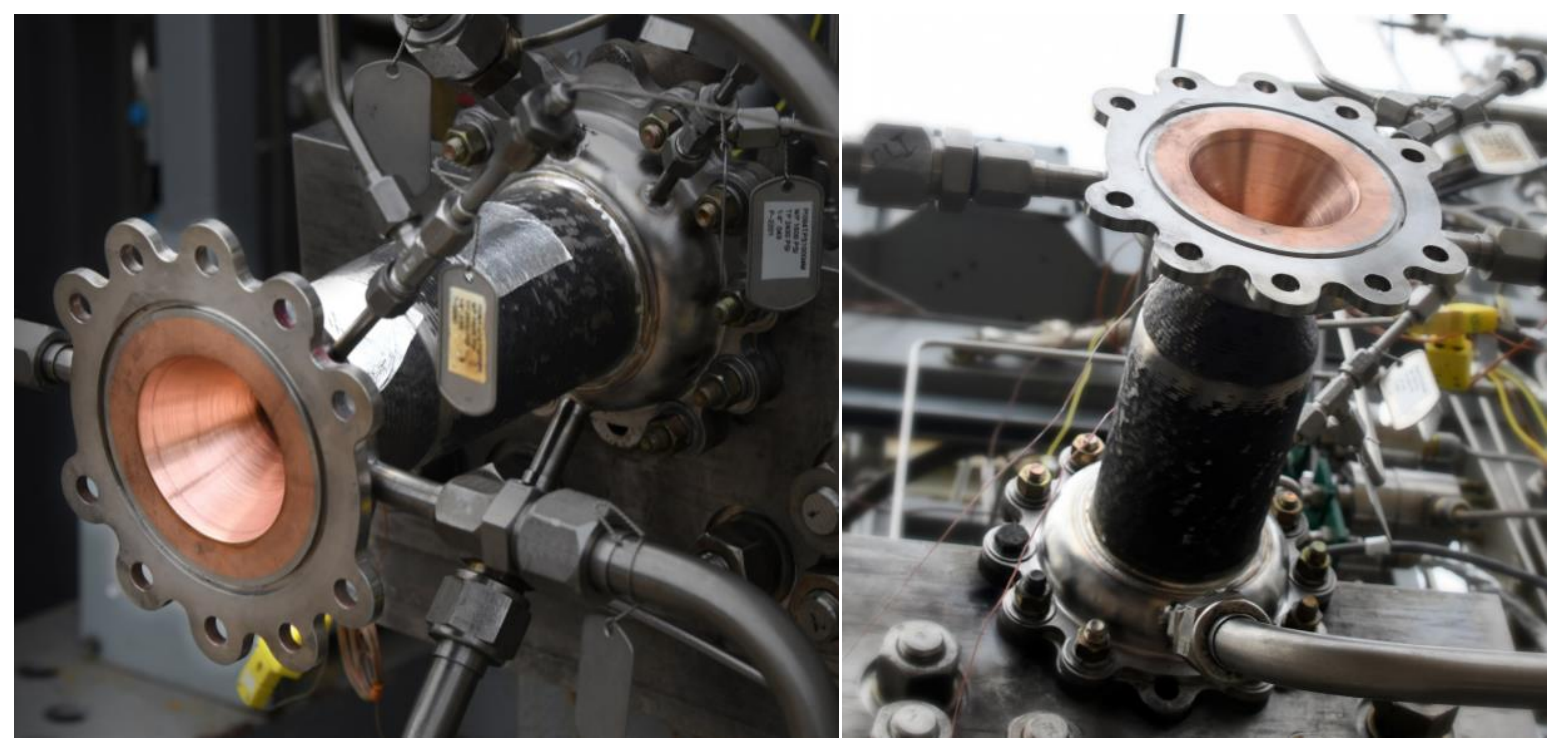

Figure 7. Chamber VO3 installed at MSFC TS115.

Over the 20 tests, performance data was collected and analyzed on each of the chambers. There were several observations about the data. The total heat load and mixture ratio summary can be seen in Figure 8. The total heat load is measured using the change in temperature $(\Delta T)$ across the liner from a series of thermocouples and pressure transducers. It was then calculated using change in enthalpy and also using mass flow calculations. From this data, the lower chamber pressure data has been omitted. The general trends met expectations for the increase in heat load with increase in MR. It was observed that the $\mathrm{C}-18150$ showed a higher heat load from the data based on the $\Delta \mathrm{T}$. Backside thermocouples were also applied onto the Inconel 625 during the test and did not show a significant difference between the different chamber units.

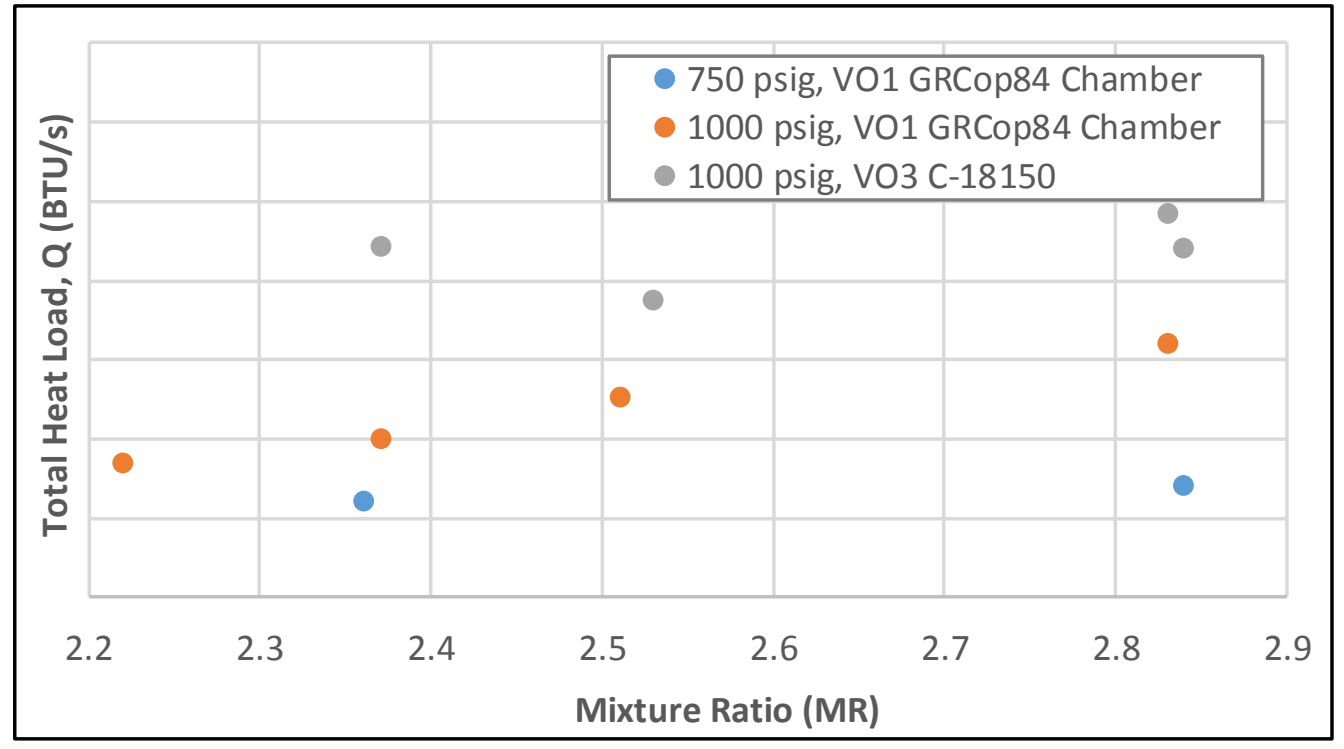

Figure 8. Summary of total heat load and MR for chamber VO1 and VO3.

Another observation from testing was the comparison of the resistances. The resistance, $\mathrm{R}$, of the chambers was calculated based on equation (1).

$$
R=\frac{\Delta P \times \rho}{\dot{m}^{2}}
$$


The resistance provides a relative comparison based on pressure drop and independent of flow rate. The comparison of resistances can be seen in Figure 9. The C-18150 liner (VO3) showed a 30\% higher resistance indicating a much higher surface roughness internal to the channels. The liners were all run in the as-built condition and channel geometry was identical.

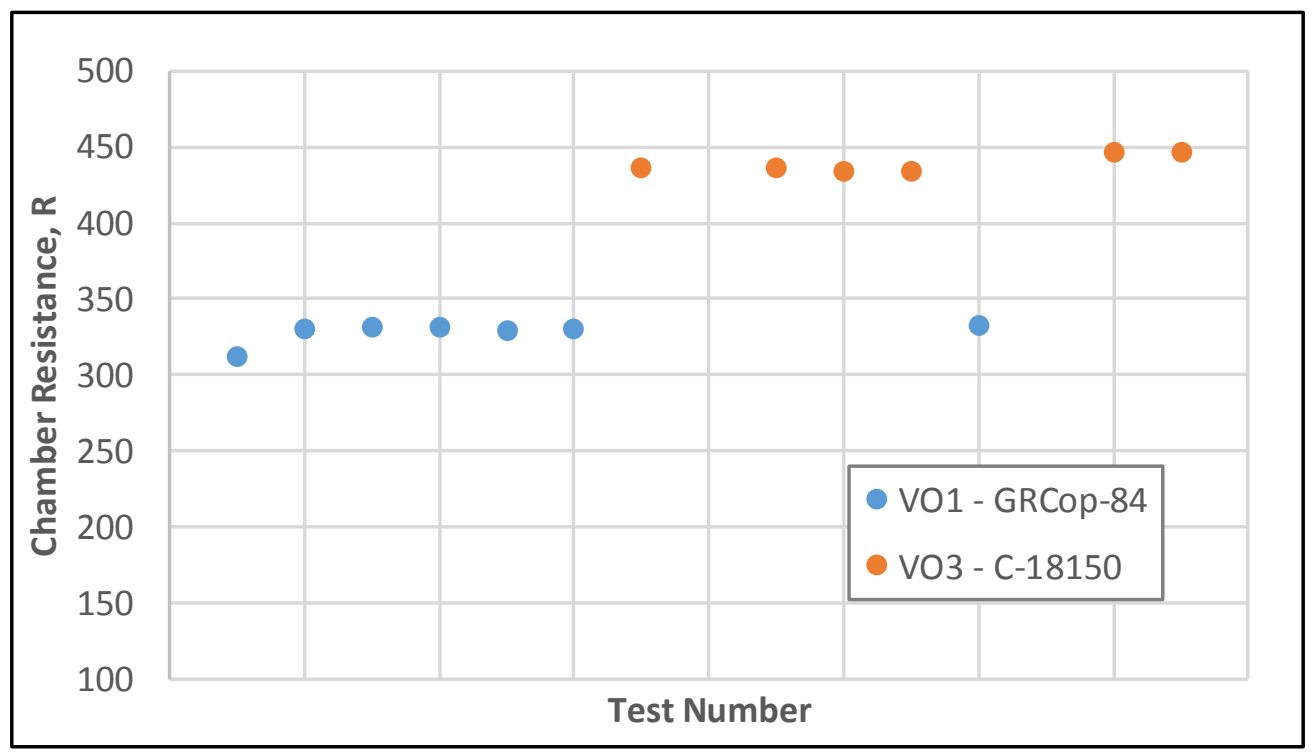

Figure 9. Chamber Liner Resistance.

An image from hot-fire testing can be seen in Figure 10. Additional piggyback testing was also completed during the test series, which included channel-cooled nozzles and high temperature Carbon-Carbon (C-C) nozzle extensions $^{18}$. An image from the C-C nozzle installed during hot-fire can be seen in Figure 11.

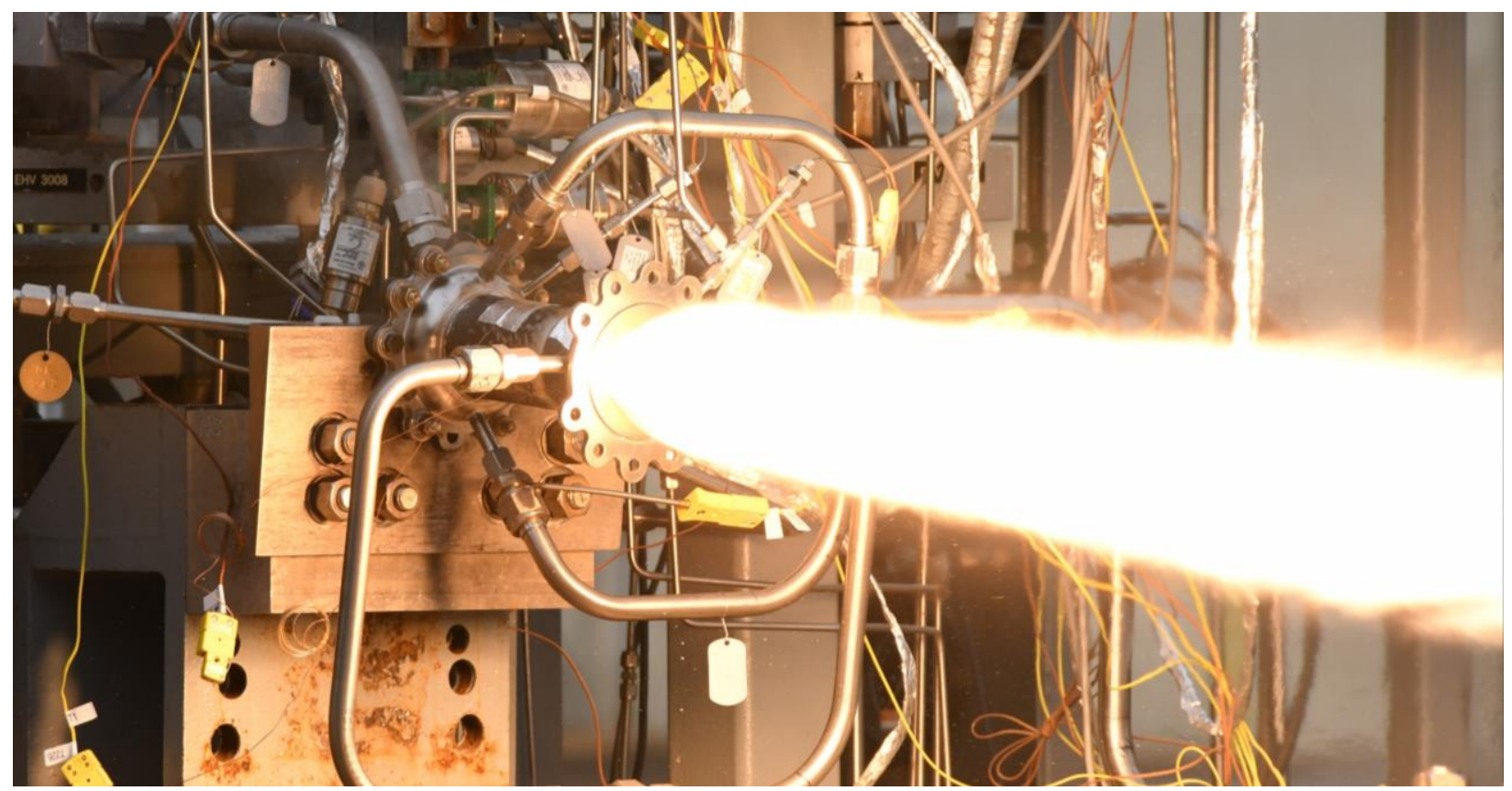

Figure 10. Image from PJ024 Hot-fire testing of the NASA/Virgin Orbit Bimetallic Combustion Chamber. 


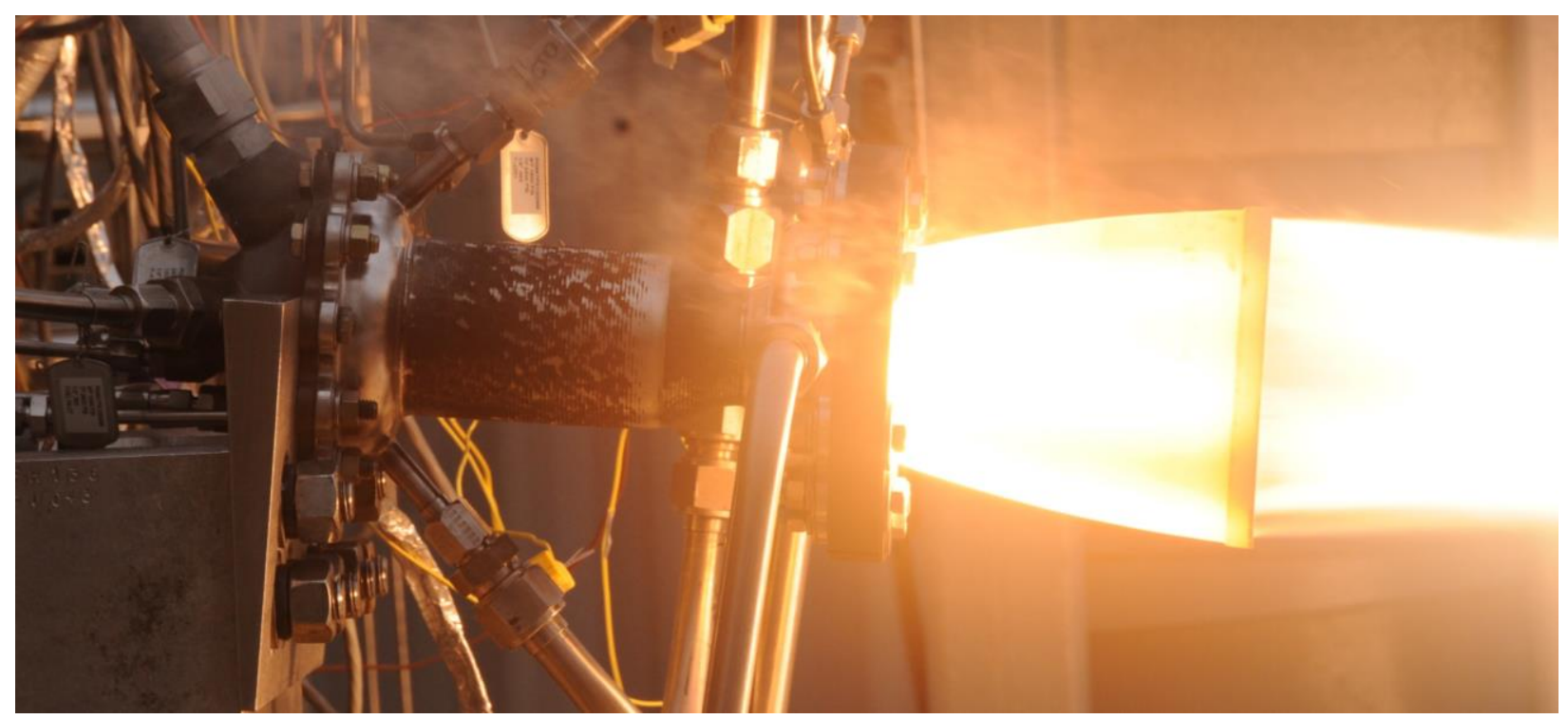

Figure 11. Image from PJ024 mainstage hot-fire testing with NASA/Virgin Orbit Bimetallic Combustion Chamber, VO3, and C-C nozzle.

\section{Conclusions}

Observations and data collected during development and testing of the $2 \mathrm{~K}-1 \mathrm{~b}_{\mathrm{f}}$ thrust combustion chambers confirmed that multi-material metal additive manufacturing is a viable fabrication method for rocket combustion devices. Two chambers were fabricated using GRCop-84 and C-18150 selective laser melting (SLM) liners and a blown powder directed energy deposition (DED) Inconel 625 structural jacket on a hybrid DMG Mori Seiki LT4300 machine. A total of 20 tests were completed under this development program. The testing demonstrated chamber pressures from 539 psig to $1,080 \mathrm{psig}$ and mixture ratios from 2.22 to 2.84 . A total of 880 seconds were accumulated on these two configurations.

Valuable data was obtained correlating flow characteristics to cooling channel surface roughness and thermal characteristics to mixture ratio as well as the copper alloy used in the liner. This information will prove essential to benchmarking additively manufactured combustion devices against traditionally manufactured ones using the same types of alloys and also serves as a stepping stone to combustion chambers of larger size and more flight-like in configuration. This program also demonstrated the successful partnership between NASA and Virgin Orbit under the Announcement for Collaborative Opportunity (ACO) program in co-developing hardware and processes.

\section{Acknowledgements}

The authors would like to thank the large team involved in the process development and hot-fire testing of the Additively manufactured bimetallic SLM/DED chambers. Thank you to Tal Wammen and the test team at Test Stand 115 for performing outstanding test support as usual. Several individuals were involved in the design, development and testing and provided critical support including Bob Widbrodt, Van Luong, and Will Bransdmeier. Thank you to our industry partners involved in this development including ASRC Federal Astronautics, Moog, and Stratasys. Thank you to the EM42 team including Ken Cooper (retired, Nampros), Megan Le Corre, Jim Lydon, Zach Jones. The GRC team including David Ellis, Laura Evans, David Scannapieco, Bob Carter, Brad Lerch (retired), Ivan Locci for continued material support of GRCop-84 and -42. Thank you to the leadership and development teams at Virgin Orbit including Robyn Ringuette, Scott Macklin, Mike Yates, and Joseph McFarlan as well as Erik Richman of EAG Laboratories. We wish to acknowledge the project offices that continue to push needs for these technologies. Also, thank you to the many other engineers at MSFC and Virgin Orbit, commercial space companies, and industry that engage in technical discussions and that have contributed to these various techniques. 


\section{References}

${ }^{1}$ Gradl, P., Greene, S., Protz, C., Bullard, B., Buzzell, J., Garcia, C., Wood, J., Osborne, R., Hulka, J. Cooper, K. Additive Manufacturing of Liquid Rocket Engine Combustion Devices: A Summary of Process Developments and Hot-Fire Testing Results. 54th AIAA/SAE/ASEE Joint Propulsion Conference, AIAA Propulsion and Energy Forum, (AIAA 2018-4625). July 9-12, 2018. Cincinnati, OH.

${ }^{2}$ Zagorski, K., Duggleby, A., Doshi, V., Gradl, P. "Hybrid Additive Manufacturing Deposition and Selective Laser Melting Techniques Applied to Copper-Alloy Liquid Rocket Engine Combustion Chambers". Presented at 5th JANNAF Propulsion Meeting (JPM)/ 10 Liquid Propulsion Subcommittee (LPS; May 21, 2018 - May 24, 2018 ; Long Beach, CA; United States)

3 Gradl, P.R., 2016. Rapid Fabrication Techniques for Liquid Rocket Channel Wall Nozzles. In 52nd AIAA/SAE/ASEE Joint Propulsion Conference (p. 4771).

${ }^{4}$ Ogbuji, L. and Humphrey, D.L., 2003. Comparison of the oxidation rates of some new copper alloys. Oxidation of metals, 60(3-4), pp.271-291.

${ }^{5}$ L.U. Thomas-Ogbuji, and D.L. Humphrey: Oxidation Behavior of GRCop-84 (Cu-8Cr-4Nb) at Intermediate and High Temperatures. NASA/CR-2000-210369, Aug. 2000.

${ }^{6}$ H. Groh III, D. Ellis, W. Loewenthal, Comparison of GRCop-84 to other Cu alloys with high thermal conductivities. J. Mater.Eng. Perform.17, 594 (2008)

${ }^{7}$ Ellis, D.L., GRCop-84: A High-Temperature Copper Alloy for High-Heat-Flux Applications, NASA/TM-2005213566.

${ }^{8}$ Gradl, P., Protz, C., Cooper, K., Garcia, C. Ellis, D.L., Evans, L.. “GRCop-42 Development and Hot-fire Testing using Additive Manufacturing Powder Bed Fusion for Channel-Cooled Combustion Chambers". 55th AIAA/SAE/ASEE Joint Propulsion Conference, AIAA Propulsion and Energy Forum. August 19-22. Indianapolis, IN. (2019).

9 Copper Development Association Inc. UNS-C18150. Retried from https://alloys.copper.org/alloy/C18150. Accessed July 10, 2019

${ }^{10}$ Bremen, S., Meiners, W. and Diatlov, A., Selective Laser Melting. Laser Technik Journal, 9(2), pp.33-38. (2012).

${ }^{11}$ Sames, W.J., List, F.A., Pannala, S., Dehoff, R.R. and Babu, S.S., The metallurgy and processing science of metal additive manufacturing. International Materials Reviews, 61(5), pp.315-360. (2016).

${ }^{12}$ Gradl, P.R., Protz, C., Greene, S.E., Ellis, D., Lerch, B., and Locci., I. "Development and Hot-fire Testing of Additively Manufactured Copper Combustion Chambers for Liquid Rocket Engine Applications", 53rd AIAA/SAE/ASEE Joint Propulsion Conference, AIAA Propulsion and Energy Forum, July 10-12, 2017. Atlanta, GA. (AIAA 2017-4670).

${ }^{13}$ Protz, C., Bowman, R., Cooper, K., Fikes, J., Taminger, K., Wright, B. Additive Manufacturing of Low Cost Upper Stage Propulsion Components. Joint Army-Navy-NASA-Air Force (JANNAF) Liquid Propulsion Subcommittee (LPS) Advanced Materials Panel (AMP) Additive Manufacturing for Propulsion Applications Technical Interchange Meeting (TIM); 3-5 Sept. (2014).

${ }^{14}$ Gradl, P., Protz, Wammen, T. "Bimetallic Channel Wall Nozzle Development and Hot-fire Testing using Additively Manufactured Laser Wire Direct Closeout Technology". Paper presented at 55nd AIAA/SAE/ASEE Joint Propulsion Conference, August 19-22. Indianapolis, IN. (2019).

${ }^{15}$ Protz, C.S., W. C. Brandsmeier, K. G. Cooper, J. Fikes, P. R. Gradl, Z. C. Jones, and C. R. Medina, D. L. Ellis,; and K. M. Taminger. Thrust Chamber Assembly using GRCop-84 Bimetallic Additive Manufacturing and Integrated Nozzle Film Coolant Ring Supporting Low Cost Upper Stage Propulsion, Paper presented at 65th JANNAF Propulsion Meeting/10th Liquid Propulsion Subcommittee, Long Beach, CA. 21-24 May. (2018).

${ }^{16}$ Anderson, R., Terrell, J., Schneider, J., Thompson, S. and Gradl, P. "Characteristics of Bi-metallic Interfaces Formed During Direct Energy Deposition Additive Manufacturing Processing". Metallurgical and Materials Transactions B, pp.1-10. (2019). https://doi.org/10.1007/s11663-019-01612-1

${ }^{17}$ Gradl, P., Protz, C., Wammen, T. “Additive Manufacturing Development and Hot-fire Testing of Liquid Rocket Channel Wall Nozzles using Blown Powder Directed Energy Deposition Inconel 625 and JBK-75 Alloys". 55th AIAA/SAE/ASEE Joint Propulsion Conference, August 19-22. Indianapolis, IN. (2019).

${ }^{18}$ Gradl, P.R., and Valentine, P.G. "Carbon-Carbon Nozzle Extension Development in Support of In-space and Upper-Stage Liquid Rocket Engines", 53rd AIAA/SAE/ASEE Joint Propulsion Conference, AIAA Propulsion and Energy Forum, July 10-12, 2017. Atlanta, GA. (AIAA 2017-5064) 